\title{
A review of the risk margin - Solvency II and beyond report by the Risk Margin Working Party
}

[Institute and Faculty of Actuaries, Edinburgh, 7 October 2019]

The Chairman (Mr G. S. Mee, F.I.A.): We have Andy Pelkiewicz and Craig Turnbull who are going to talk to you about risk margin. Andy (Pelkiewicz) will give you a good summary and take you through the main points. Craig (Turnbull) will then provoke some discussion.

Andy (Pelkiewicz) spent most of his career at Sun Life, and then AXA Sun Life. In 2007, he joined HBoS, which later became part of the Lloyds Banking Group, within their European life business. He was heavily involved in the development of Solvency II for companies in Germany, Luxembourg and the UK. That took him to Germany in 2010, where he was later head of actuarial and investment at the Heidelberger Leben Group. He retired in 2016 and continues to live in Germany.

Mr A. J. Pelkiewicz, F.I.A.: The working party was set up in 2017 following criticisms of the risk margin, in particular in the Treasury Committee inquiry into EU insurance regulation. Our brief was in two parts: what fixes can be made, either under Solvency II or, in the UK, post-Brexit; and a more general examination of the purpose of the risk margin and how it can be fulfilled.

In addition to the members of the working party, I would like to mention Chris Marsh, who was our first chair and set us off in the right direction before leaving the working party last year.

As well as preparing the paper, we have developed a simple model to illustrate the issues, and we have also carried out a survey of insurers. These are described in the paper, and the results are used to illustrate the points made in the paper.

What is the purpose of the risk margin and how did it develop? I would like to describe this by giving a light-hearted imaginary description of how the legislators might have thought, so do not take it too seriously. The paper does give a more formal description.

Let us imagine, for a moment, that I am a legislator and I am trying to design a modern international solvency system. I might start with a principle that the valuation methodology must be as prescriptive as possible. In this vision, I do not want companies or their actuaries using more judgement than necessary. This principle is followed by market consistent valuation, which is widely used, so let us choose that. It is easy to value assets but not liabilities. There is no deep, liquid market in insurance liabilities. To be market consistent, we need to estimate the amount the firm would have to pay in the market to transfer its liabilities.

The best estimate - the expected value of the liabilities - can readily be calculated, but the transferee would want more. After all, he is taking on a risk, he is having to provide regulatory capital and he wants to make a profit. So, I need to define a proxy for the market costs of the transfer value in excess of the best estimate, and there are a number of possible approaches. For the solution, I consider valuing the risks incurred and also the cost of capital required. I consult with the industry and I look at other solvency regimes.

In the end, I decide to follow the wishes expressed by the industry and copy the solution of a neighbouring country, in this case Switzerland. Therefore, I define the proxy addition as the cost of capital in the transferee company over the full run-off period. 


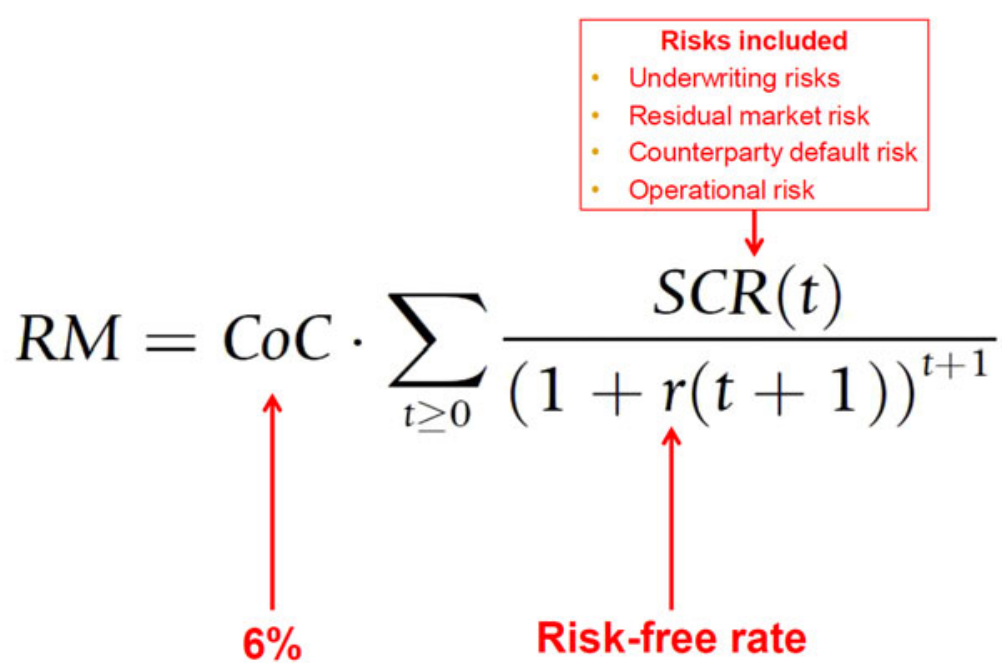

Figure 1. The Solvency II risk margin formula.

I need to make some assumptions about the transferee company. In the real world, business would likely be transferred to a consolidator, but it would be extremely difficult to define the characteristics of a consolidator in valuation regulations. That would require the use of much judgement.

Perhaps we could assume that the transfer is to the original company? We can achieve a similar effect by assuming that the transferee company is empty before the transfer, is closed to new business, de-risks its assets and adopts all practices and management actions of the original company. I will do that and I will call the company the reference undertaking; not very realistic, but satisfyingly prescriptive.

That is how I like to imagine the risk margin might have developed.

The formula in Figure 1 is taken from the Solvency II regulations for calculating the risk margin and represents the cost of future capital after a transfer to the reference undertaking. You will immediately observe that it depends on a number of explicit assumptions.

The cost of capital is fixed at a rate of $6 \%$ above the risk-free rate. The discount rate is the normal risk-free rate. The reference undertaking is as I have described. All of these assumptions have a significant impact and could, indeed should, be challenged.

There is also an important implicit assumption. I have explained the risk margin as being part of market consistency, but it can also be explained as being part of policyholder protection. The Solvency II capital requirement allows the firm to survive a 1-in-200-year event in the next year. The risk margin is the link to the future beyond that. You can see from the structure of the formula that it covers the cost of capital in each future year. If everything happens in line with the assumptions, this capital would be required. However, it also assumes that the firm would be recapitalised after a 1-in-200-year event to full Solvency II standards, awaiting the next 1-in-200-year event, and the next. So the implicit assumption is that, following failure, Solvency II standards would still apply.

That is desirable for customer protection, but a large risk margin adds cost to customers, and relaxing the future solvency standard following failure could reduce the risk margin. Balancing costs against policyholder protection is a political question, and it was covered as such in the Treasury Committee, though the politicians did make it clear that they look for expert advice. It does not seem to have been raised as a political question within the EU. 


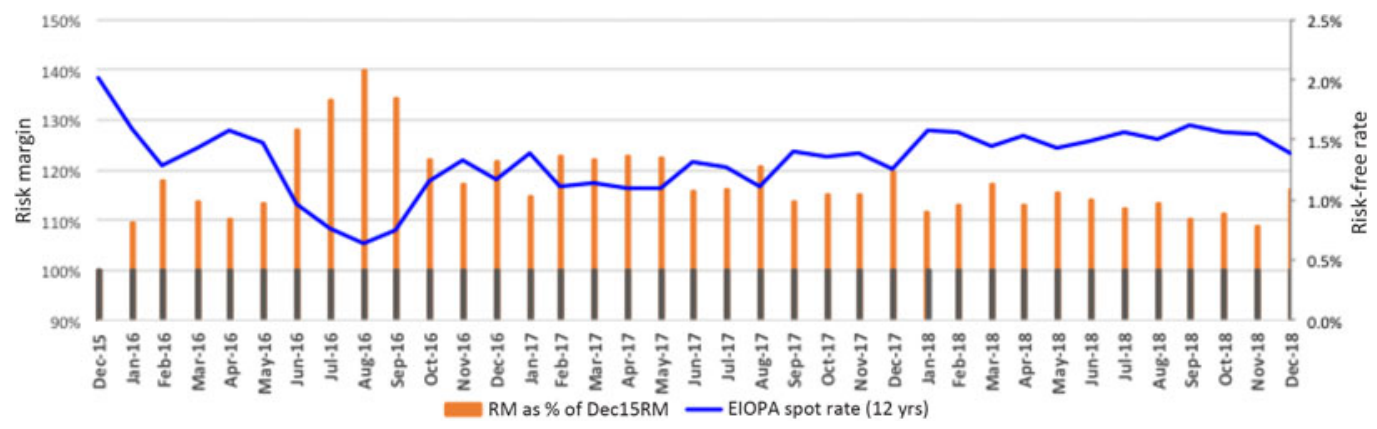

Figure 2. Variation of risk margin with risk-free rates.

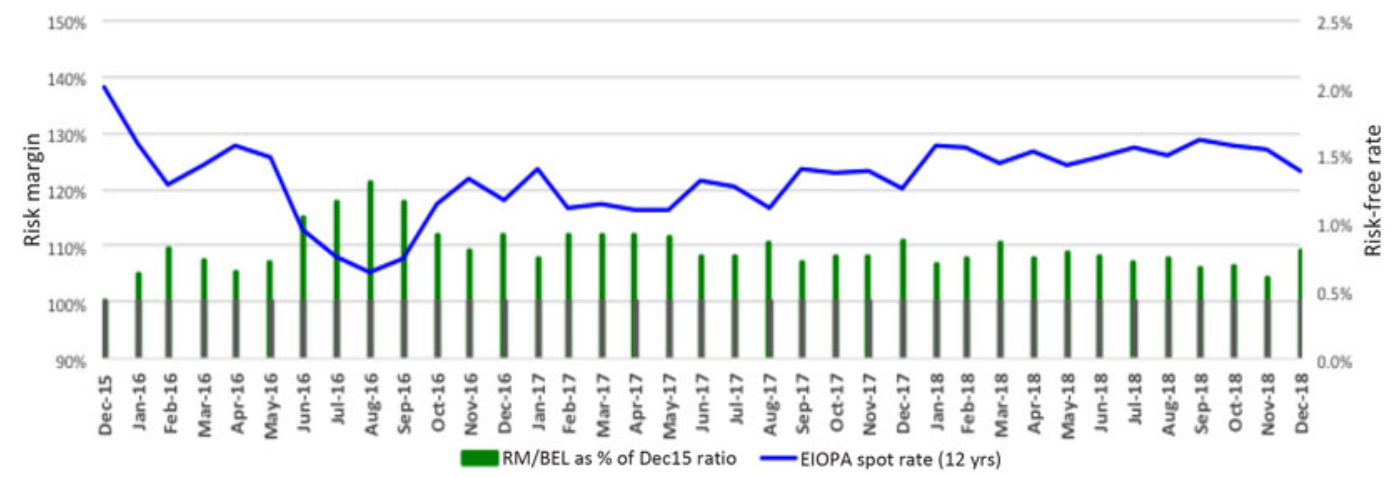

Figure 3. Variation of risk margin as a proportion of best estimate liabilities (BEL) with risk-free rates.

What are the problems with the risk margin? Shortly after the implementation of Solvency II, long-term interest rates fell sharply, and it became clear that the risk margin was not only large but extremely sensitive to interest rate movements, particularly for annuity business.

Annuities, both individual annuities and bulk purchase annuities, are very important to the system of UK retirement provision. They form a major product for the life insurance industry. That means that the risk margin is very much a UK problem. The scale of the problem is demonstrated by statements in 2017 from the Prudential Regulatory Authority (PRA). Between December 2015 and September 2016, the overall risk margin of major UK life firms rose from $£ 30$ billion to $£ 44$ billion.

The impact can also be seen in the results of our model, which is of a monoline annuity firm.

Figure 2 shows the monthly variation of the modelled risk margin, which we have expressed as a percentage of December 2015, and for comparison shows the 12-year risk-free rate. It demonstrates extreme volatility.

We have also modelled the risk margin as a percentage of best estimate liabilities, as shown in Figure 3, and it is also volatile though not as volatile as the amount in pounds.

Of note here is that the base of $100 \%$ is in December 2015 when the ratio was $7.7 \%$, so the risk margin thereafter is around $8 \%$ to $9 \%$ of the best estimate, which is a significant burden. Our model uses the standard formula to determine the risk margin. Internal model risk margins are likely to be higher still. This is likely to be affecting the pricing of annuities, with adverse consequences for retirement provision. However, the PRA claimed, in its response to the Treasury 


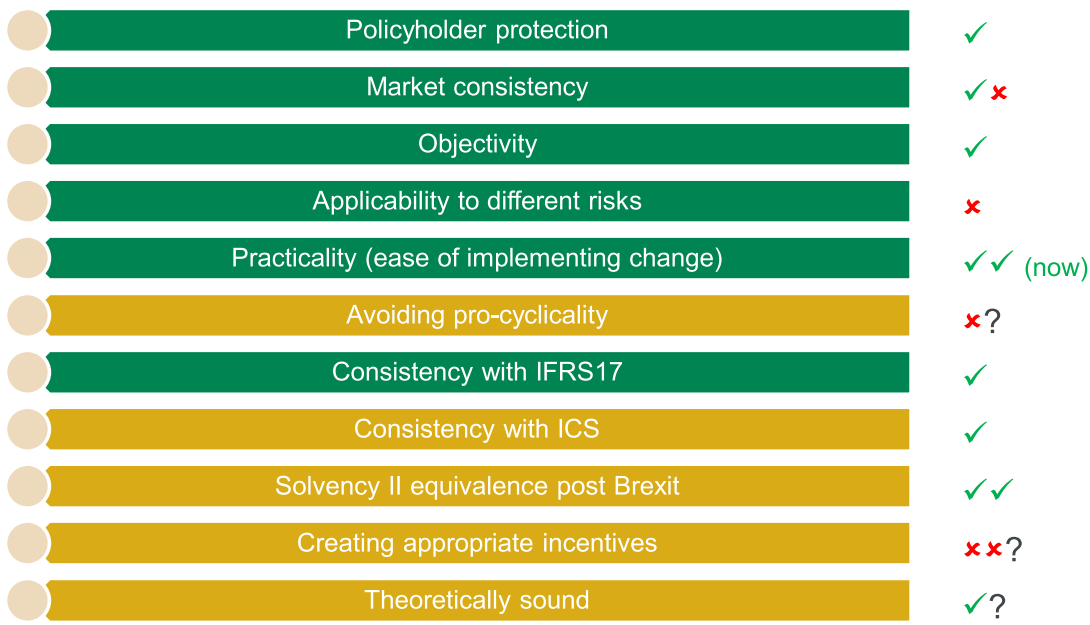

Figure 4. Qualities of a desirable risk margin.

Committee, that there was no evidence of a change in annuity rates relative to interest rates in the period after Solvency II was introduced.

Another concern is that the size and volatility of the risk margin is encouraging firms to reinsure longevity risk outside the EU, because that reduces and stabilises the risk margin.

What has been happening as a result of problems? The Treasury Committee inquiry took place in 2016-17 and the risk margin was a major theme. Andrew Chamberlain gave evidence on behalf of the Institute and Faculty of Actuaries (IFoA) and dealt with some pertinent questions. I would recommend watching the video. The Committee's report concluded that a risk margin makes conceptual sense and should continue to form part of the UK regime. However, they recommended that the PRA should provide a solution to improve its calibration.

The initial PRA response was that it was actively looking at improving calibration, but a later statement, in June 2018, was to the effect that no changes can be made pending further clarity on Brexit, and that remains the case to this day. The European Insurance and Occupational Pensions Authority (EIOPA) also carried out a review of Solvency II regulations in 2017-18, and the working party contributed to the IFoA's submission to the consultation. In the case of the risk margin, we were disappointed to find that the scope of the review was limited to the $6 \%$ cost-of-capital rate. Our comments were much wider than that.

EIOPA's conclusion in its limited review was that the rate should probably be even higher than $6 \%$, somewhere between $6.7 \%$ and $7.8 \%$. They did not recommend an increase at that time. Some of the assumptions they used in reaching the conclusion could certainly be challenged. Within the working party, we have differing views on the level of the rate, although I do not think anybody thinks that $6 \%$ is too low.

The next review is due next year, and the European Commission has sent a formal request to EIOPA to carry it out. Disappointingly, the request limits the scope to the cost-of-capital method, but it does require consideration of factors other than the cost-of-capital rate.

What are our solutions to the problems? First, we asked ourselves what qualities should the risk margin possess?

Referring to Figure 4, 6 of the 11 elements are the original principles set out by the Groupe Consultatif in 2006 when Solvency II was being designed. We have added five more. We have also assessed how the current risk margin shapes up. 


\begin{tabular}{|c|c|c|}
\hline Proposal & Justification & What needs to change \\
\hline $\begin{array}{l}\text { Lower cost of capital } \\
\text { from } 6 \%\end{array}$ & Simplest change to reduce magnitude of issue & Level II Delegated Acts \\
\hline $\begin{array}{l}\text { Vary cost of capital with } \\
\text { interest rates }\end{array}$ & $\begin{array}{l}\text { Reduces (artificial) volatility } \\
\text { and some theoretical evidence }\end{array}$ & Level II Delegated Acts \\
\hline MA or VA used for SCR & $\begin{array}{l}\text { Consistent with BEL } \\
\text { (but market risk was assumed to be de-risked) }\end{array}$ & EIOPA Guidelines \\
\hline $\begin{array}{l}\text { MA or VA used to } \\
\text { discount cost of capital }\end{array}$ & $\begin{array}{l}\text { Insurer should be able to earn illiquidity } \\
\text { premium on capital held }\end{array}$ & Level II Delegated Acts \\
\hline Tapering of lifetime risks & Lifetime risks are not independent & $\begin{array}{l}\text { Level II Delegated Acts } \\
\text { or Internal Model }\end{array}$ \\
\hline $\begin{array}{l}\text { Link to reinsurance } \\
\text { pricing }\end{array}$ & $\begin{array}{l}\text { Market consistent } \\
\text { and removes artificial incentives to transfer }\end{array}$ & $\begin{array}{l}\text { Level II Delegated Acts } \\
\text { or PRA acceptance of } \\
\text { management action }\end{array}$ \\
\hline
\end{tabular}

Figure 5. Options for change - within Directive.

Policyholder protection is being delivered, but is it cost-effective? On market consistency, the risk margin was constructed to be theoretically market consistent, but it is not market consistent in practice. It does not behave in line with market pricing: it is too volatile.

On objectivity, or consistency between firms, there is a single method, so it is largely achieved. On the other hand, risk margin is based on a capital requirement, which can vary between different internal models. There is also the question of diversification. The level of diversification assumed is what is in the original firm, not what could be achieved post-transfer. That could understate the potential diversification benefit.

Applicability to different risks: it seems to be particularly penal to long-dated risks, I would say this is largely because of the discount rate being risk-free.

Practicality of calculation: the calculation is very complex. The problem has already been solved by firms through necessity, but it does seem unsatisfactory that such a large item like the risk margin must normally be determined through approximate methods. We cover this complexity briefly in an appendix to the paper.

Avoiding procyclicality would only be an issue if the volatility of the risk margin drives companies' behaviour, which itself drives markets. We do not think there is much evidence of that to date.

On consistency with International Financial Reporting Standards (IFRS) 17, IFRS 17 has a risk adjustment which forms the same function. It allows the cost-of-capital method but it does not require it.

Similarly, the use of the cost-of-capital method is consistent with international capital standards.

On Solvency II equivalence post-Brexit, clearly, if it is not changed in the UK post-Brexit, it would not form a barrier to equivalence.

Creating incentives: the PRA has expressed particular concern about offshore reinsurance of longevity risk, but the fact that UK insurers reinsure longevity, particularly to the USA where it can be diversified against life insurance for older people, is not necessarily a bad thing. Monoline annuity insurers were making use of reinsurance before Solvency II. There does, however, seem to be some evidence that, at least for some insurers, the reinsurance decision is driven by the risk margin and regulatory arbitrage.

Finally, is it theoretically sound? It is possibly too theoretical, and not practical enough, and it requires simplifying assumptions and approximations. 
We considered a number of changes which might be made within the terms of the existing Directive.

Figure 5 shows what the proposals are and, in the last column, what would have to be changed in Solvency II.

The first suggestion is to reduce the cost-of-capital rate from $6 \%$, a simple solution. As I said before, EIOPA have produced a robust defence of the $6 \%$ rate. The second suggestion is to allow the costs-of-capital rate to vary with interest rates. There does seem to be some evidence that this might be the case. Work done by the Chief Risk Officers forum while Solvency II was being developed suggested a fall of 100 basis points in the risk-free rate would reduce the cost-of-capital rate by 30 to 40 basis points.

Allowing for the matching adjustment or volatility adjustment, which are not used in the risk margin, could be made in two different places. They could be used to calculate the Solvency Capital Requirement (SCR), and they could be used to discount the cost of capital. To use them for the SCR would require the reference undertaking to use the same adjustment as the original insurer. That sounds reasonable, but the whole basis of the risk margin is that credit risk is removed and you would have to add it back in, particularly if you use a matching adjustment. Perhaps there is a better case for using the volatility adjustment, if it was argued this could be earned via pure liquidity premiums with no credit risk at all.

The tapering of lifetime risks is quite an interesting idea. The risk margin formula assumes that the risks are independent from year to year. There is an argument that that overstates lifetime risks. Just as an example, a 1-in-200- year longevity risk must require something pretty major to happen. An example might be development of a cure for many cancers.

Following such a development, the scope for future improvements is likely to be reduced. You can only develop the same cure once. The Association of British Insurers (ABI) has suggested allowing for this pragmatically by reducing future SCRs in a way that is similar to discounting at a higher than risk-free rate.

Finally, a link to reinsurance pricing. Solvency II refers to the amount a reinsurance undertaking would have to pay if it transferred its contractual rights and obligations immediately to another undertaking. So, if the longevity market is sufficiently liquid, why not use the price of longevity reinsurance in the same way as is done for market risks? Indeed, in the original draft Solvency II rules, they referred to hedgeable risks and non-hedgeable risks, and that changed at some point.

All insurance risk is now included in the risk margin calculation under the Solvency II regulation. The ABI has proposed a management action solution under existing rules. The company would have a management action to effect longevity reinsurance following asset de-risking.

Figure 6 shows the results of our model and the various changes that we made. We have made the assumption that the reinsurance pricing is going to be cheaper than the cost of capital used in the risk margin. However, reinsurance pricing is not readily available. For this example, we assumed the equivalent cost-of-capital rate is $3.5 \%$.

In the two bars with the matching adjustment, we have added back credit risk. We see that in both cases using the matching adjustment increases the risk margin when you add back credit risk, which logically you should.

So far as volatility is concerned, Figure 7 is the same as Figure 3, with an additional split of the risk margin to show the impact, in the red bars, if you assume the cost-of-capital rate is $6 \%$ in December 2015, but reducing by 35 basis points for every $1 \%$, following long-term yields. The green bar takes it back up to a cost-of-capital rate of $6 \%$.

In Figure 8, we have assessed the alternatives against our 11 criteria. It is rather subjective, and we do not intend it to be used as a score. It does highlight the key issues.

For example, reducing the cost-of-capital rate is the simplest change. It has had push back from EIOPA. 


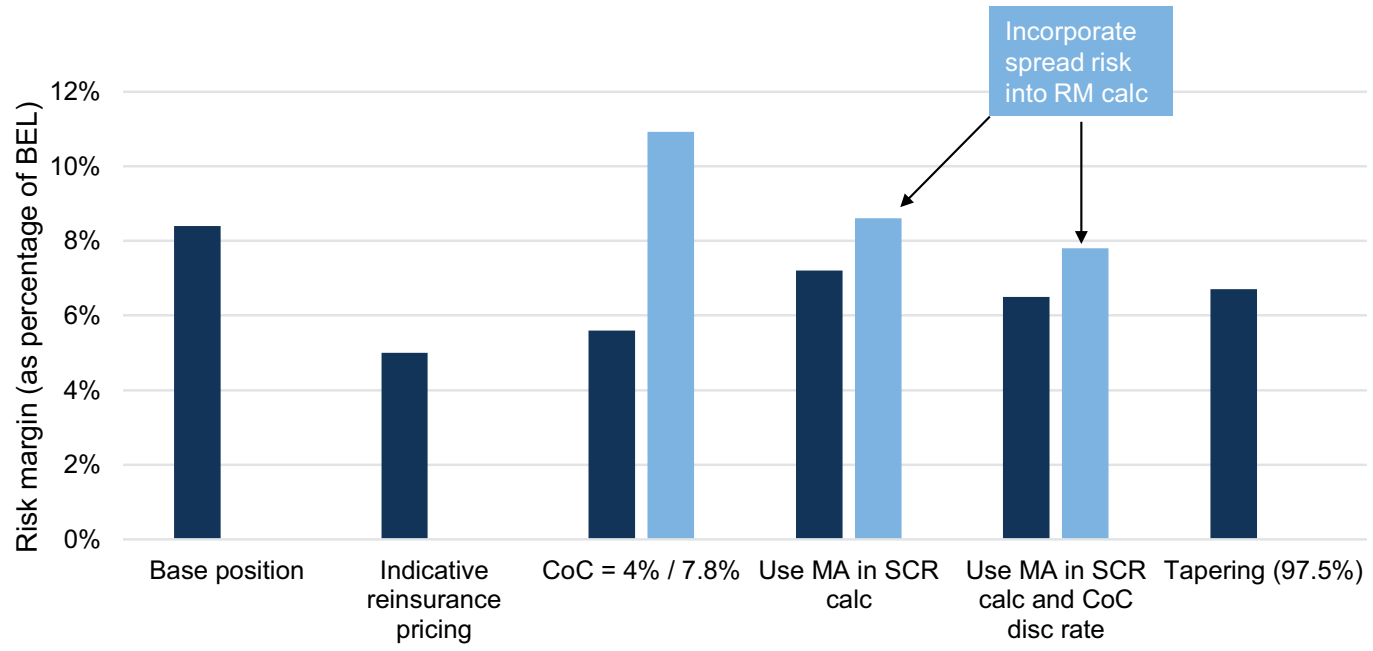

Figure 6. Comparing options - magnitude.

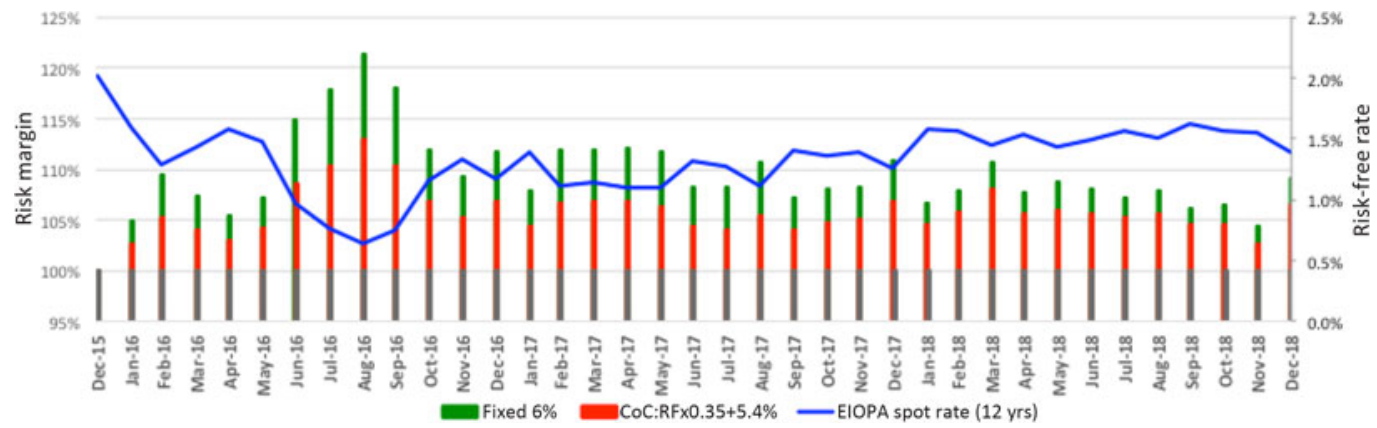

Figure 7. Comparing options - volatility.

\begin{tabular}{|c|c|c|c|c|}
\hline & Reduce CoC & $\begin{array}{l}\text { CoC varies } \\
\text { with rates }\end{array}$ & $\begin{array}{l}\text { Allow for MA } \\
\text { or VA }\end{array}$ & $\begin{array}{l}\text { Cost of } \\
\text { reinsurance }\end{array}$ \\
\hline Policyholder protection & $x$ & $?$ & $x$ & $\checkmark ?$ \\
\hline Market consistency & $?$ & $\checkmark ?$ & $?$ & $\checkmark \checkmark$ \\
\hline Objectivity & - & - & - & $x ?$ \\
\hline Applicability to different risks & - & - & - & $x x$ \\
\hline Ease of implementing change & $\checkmark \checkmark$ & $x$ & - & $?$ \\
\hline Avoid pro-cyclicality & $\checkmark ?$ & $\checkmark \checkmark$ & $\checkmark$ & $\checkmark x$ \\
\hline Consistency with IFRS17 & - & - & $\checkmark$ & $x$ \\
\hline Consistency with ICS & $x ?$ & $\checkmark$ & $\checkmark ?$ & $x$ \\
\hline Solvency II equivalence & $x ?$ & $?$ & $\checkmark$ & $\checkmark ?$ \\
\hline Appropriate incentives & $\checkmark$ & $\checkmark$ & - & $\checkmark \checkmark$ \\
\hline Theoretically sound & $?$ & $\checkmark ?$ & $\sqrt{ } x$ & $\checkmark \checkmark$ \\
\hline
\end{tabular}

Figure 8. Assessing the alternatives (1). 
A varying cost-of-capital rate is maybe an alternative. International capital standards field tests have looked at that as an alternative. They have looked at a cost-of-capital rate above the risk-free which is 3\% plus risk-free. Instead of the 35 basis points sensitivity, they have assumed 100 basis points, which would make hedging a bit difficult.

Using the matching or volatility adjustment helps dampen market moves, but you do have to allow for the cost of capital against credit risk.

Reinsurance pricing is market consistent by definition, but how practical and objective is it? The longevity reinsurance market is arguably deep and liquid, but certainly it is not transparent. Reinsurance pricing is dependent on an individual firm's exposure. One possibility might be a simple factor-based solution to longevity SCR based on prudent estimate through-the-cycle reinsurance pricing. It would work for some longevity risk. It would not work for other risks, for example, lapse risk, or indeed longevity for deferred annuities.

We also considered some more radical changes, probably of more relevance to the UK postBrexit than for the EU.

Traditionally, when faced with uncertainty and assumptions, actuaries have used prudent margins above the best estimate. Outside the EU, this seems to be re-emerging as an approach under new solvency regimes.

There seem to be several different philosophies, and we have identified three distinct approaches. One is an explicit percentile, for example, a 75th percentile in terms of best estimate liabilities. That was tested when Solvency II was designed. It is a method which is used for general insurance in Australia.

Another is regulatory prescribed margins on individual assumptions. What is emerging as an alternative to the cost-of-capital method under international capital standards is a percentile margin over current estimate.

Essentially, it is similar to the SCR but calibrated to a lower level and for non-hedgeable risks only. The simple calibration that is being tested produces a risk margin of $26 \%$ of the SCR for the same risks.

Another approach is to simply allow for a run-off of the liabilities and include both the SCR and the risk margin in the technical provisions. Essentially, it is an approach which is being proposed by the Department for Work and Pensions in their consultation for pensions consolidation vehicles or super funds. It is also a test which is applied alongside Solvency II in the non-life Lloyds market.

Finally, no risk margin. Individual capital adequacy standards in the UK before Solvency II did not have a risk margin. Once a 1-in-200-year event has happened and you have lost the SCR, should policy holders really expect more than a 50/50 chance of meeting liabilities? The working party's view is that they should.

How do we assess these more radical alternatives? Again, we have made a tick/cross assessment. We have included no risk margin in Figure 9, even though we feel it is inappropriate, and also the Treasury Committee explicitly rejected it. IFRS and international capital standards both require a risk margin equivalent. So, no risk margin seems to be off the agenda.

The run-off capitalisation approach has some technical attractions. It would require a very major change to the regime, and it is not going in the same direction as international trends. However, in international capital standards, it does seem that the cost-of-capital method is beginning to lose the battle in the direction of prudent margins. Post-Brexit, for example, if the UK wishes to seek equivalence in Solvency II, it may be able to argue that adopting variants allowed in international capital standards should not threaten equivalence.

What are our conclusions as a working party? The first point is we have not felt able to propose a single solution. It is a very complicated question. What could change, particularly in the UK, depends on the outcome of Brexit and on other developments. However, we do feel that some of the things that we have identified should be considered depending on circumstances, both in the $\mathrm{UK}$ and, indeed, in future reviews in the EU. 


\begin{tabular}{|c|c|c|c|c|}
\hline & Run-off \%ile & $\begin{array}{l}\text { VaR } \\
\text { (P-MOCE) }\end{array}$ & $\begin{array}{l}\text { Run-off } \\
\text { capitalisation }\end{array}$ & $\begin{array}{l}\text { No risk } \\
\text { margin }\end{array}$ \\
\hline Policyholder protection & - & - & $\checkmark$ & $x x$ \\
\hline Market consistency & $?$ & $?$ & $?$ & $x$ \\
\hline Objectivity & - & - & $x$ & $\checkmark$ \\
\hline Applicability to different risks & - & - & - & $\checkmark$ \\
\hline Ease of implementing change & $x$ & $\checkmark$ & $x x$ & $\checkmark \checkmark$ \\
\hline Avoid pro-cyclicality & - & - & $\checkmark \checkmark$ & - \\
\hline Consistency with IFRS17 & $\checkmark$ & $\checkmark ?$ & $x$ & $x x$ \\
\hline Consistency with ICS & $x$ & $\checkmark$ & $x x$ & $x x$ \\
\hline Solvency II equivalence & - & $\checkmark ?$ & $x ?$ & $x x$ \\
\hline Appropriate incentives & $?$ & $?$ & $?$ & $x$ \\
\hline Theoretically sound & $\checkmark ?$ & $x ?$ & - & $x$ \\
\hline
\end{tabular}

Figure 9. Assessing the alternatives (2).

We have four possible options for change:

1. To allow for an automatic change in the cost-of-capital rate when risk-free rates change.

2. To allow a prudent illiquidity premium to be used in the calculations of projected future SCRs, and in the risk-free rate used in discounting the future cost of capital. That is more relevant to the volatility of adjustment than the matching adjustment.

3. To allow certain longevity risks to be treated as hedgeable, and the relevant part of the risk margin to be replaced by the cost of the hedge.

4. To either move to, or allow as an alternative, the percentile margin over current estimate, which is currently being tested under international capital standards.

That is a summary of the paper. The paper has a lot more detail. I hope you found it interesting and that it will lead to an interesting discussion.

Mr C. J. Turnbull, F.I.A. (opening the discussion): I am an insurance solutions director at Aberdeen Standard Investments. I am a member of the IFoA's Equity Release Mortgages Working Party and author of a book called the History of British Actuarial Thought. On behalf of everyone, I should like to thank Andy (Pelkiewicz) and the working party and offer congratulations for an excellent and timely paper. The paper provided a comprehensive study of the subject of Solvency II's risk margin. It covers the background behind its development, the questions surrounding how it is calibrated, the many practical matters around how it is implemented, some potential solutions to those issues, and also alternatives to the cost-of-capital approach that it uses. The papers also provide some current industry perspectives on how to manage the financial consequences of the risk margin.

It is presented in a very accessible and concise way, whilst being very balanced and rigorous. I recommend it to anyone who wishes to understand the risk margin topic. The paper provides us with an excellent platform for an informed discussion and I will now offer a few thoughts on the risk margin topic.

My personal view is that the cost-of-capital methodology that is used in Solvency II is a coherent and insightful way of modelling a market consistent value and insurance contract that does have cash flows with non-hedgeable uncertainty. In such circumstances, any financially secure entity must hold capital in excess of the best estimate liabilities to support those risks over the 
lifetime of the contract. The capital has a cost which must be reflected in the exit value of the contract. That is the essence of the cost-of-capital method which gives us the risk margin.

My own feeling is the concept fits naturally into our framework with Solvency II. Even if we were starting again with a blank piece of risk margin paper, I still feel the cost-of-capital approach would be the naturally preferred methodology. Alternative approaches are explored in section 7 of the paper, such as a run-off percentile approach and others.

They are all perfectly reasonable approaches to assessing risk, but none of them fit quite so coherently into the idea of the 1-year value-at-risk at the heart of Solvency II and its need for an exit value measure. I would argue that the cost-of-capital methodology is a conceptually elegant solution to the Solvency II question of how to treat unhedgeable risks in liability valuation. But it is also a highly abstract way of empirically estimating a current exit value for an insurance contract.

There is a risk, when making use of such an abstraction to deliver real-world insight, and especially when using it to determine the quantitative value of a real-world quantity, that the logic of the abstract model is misapplied. The Solvency II implementation of the cost-of-capital method is open to that charge, and the result is that the Solvency II risk margin is generally materially larger than it ought to be.

There are a couple of key areas in the Solvency II implementation where errors have occurred. In the interest of time, I will focus on one in particular, and that is the calibration of the cost-ofcapital rate. Before I do that, I will first touch on another difficult topic that rises in the context of the risk margin, and that is how we determine what risks should be incorporated into the risk margin. Put another way, what do we mean by non-hedgeable risks?

Longevity risk provides a very interesting and topical example. The working party notes that a deep and efficient market for longevity risk transfer exists in the UK and elsewhere and is used regularly by insurers to transfer longevity risk to reinsurers. They also note that the pricing of such transactions is not in the public domain. This is a significant barrier to the use of these prices as a direct estimate of current exit values.

The paper also notes that some of the non-hedgeable risks that insurers undertake will not be readily accepted by reinsurers. Consequently, the need for some form of abstract modelling approach to the assessment of the risk margin seems unavoidable to me.

As I will argue shortly, the correctly implemented cost-of-capital calculation would reconcile much more closely with anecdotal estimates of reinsurance pricing than current risk margins. It might also be noted that in Solvency II it has been determined that some significant forms of financial market risk exposure in EU insurance balance sheets do not trade in deep, liquid and transparent markets. It has also been determined that the capital that must surely follow from holding those risks should not be included in the calculation of the risk margin.

The 30-year risk-free Euro interest rate is perhaps a particularly interesting example. In the apparent absence of a reliable market price for the 30-year interest rate, Solvency II uses best estimate assumptions, to build the Euro yield curve out from beyond 20 years. No risk margin is held, but there will be a cost of capital that must presumably be held for the substantial residual risk that arises in the absence of such instruments.

What is the difference between longevity risk and this long-term interest rate risk? In both cases, I think we are saying there is a market for risk transfer, but its pricing is not transparent and we therefore have to revert to best estimates, rather than market rate assumptions, to value our liabilities.

In one case, for the longevity risk, the insurer must hold a risk margin. In the other case, longdated European interest rate risk, the insurer does not.

Moving on to my critique of the cost-of-capital methodology, I believe that the choice of $6 \%$ as the cost-of-capital rate is a technical error in the Solvency II implementation. As the working party notes, it is an assumption that can be traced back to a 2006 paper related to the Swiss Solvency Test. Most actuaries who have read that paper will agree with the working party's description of the paper's justification of the $6 \%$ parameter choice as superficial. Yet it has stuck and since then 
EIOPA has sought to justify this choice of parameter with reference to a historical estimate of the equity risk premium. Others have then argued that it should be more appropriate to use a forward-looking estimate of the risk premium. Others have argued that the insurance sector has a beta greater than one and that should be incorporated into the overall assessment of the insurance sector's risk premium.

But the economic theory underlying the cost-of-capital method has nothing to do with the equity risk premium. As in any other market consistent valuation, the size of the risk premium is irrelevant. The economic logic behind the cost-of-capital methodology is that the cost is there to compensate shareholders for their capital being tied up in the reference entity's balance sheet rather than sitting in their own account. To the extent that this capital is exposed to equity risk, the equity risk premium will be both expected and required. The valuation of the costs of holding the future capital must allow for the earnings that the capital is expected to generate, as well as the risk premium that should be incorporated into the total cost of that capital. The equity risk premium cancels out.

The theoretical argument for the irrelevance of the equity risk premium here is even simpler, when we think about it in the context of the reference entity that is stipulated in the Solvency II regulations. As explicitly defined in those regulations, this entity is a hypothetical entity with some very specific properties. It does not have any other business on its balance sheet other than the business it will acquire from the insurance firm. The reference entity will hedge any, and all, financial market risk exposures that it acquires through obtaining insurance from its business. So, by design, the reference entity unambiguously has, from its explicit characterisation in the Solvency II regulations, a zero beta balance sheet. It looks nothing like a typical European insurance company, and nothing like the index of corporations that has been used in the EIOPA calibration for the cost-of-capital parameter. The only compensation required by the shareholders of the reference entity is for the frictional costs incurred tying up their capital on the reference entity's balance sheet, rather than holding it directly.

Now this frictional cost-of-capital idea is not a new idea in economics. It has been around for a very long time. Conventionally, it has three components. These are the costs of double taxation, agency costs and the costs of financial distress. The double taxation effect can be estimated as the marginal corporate tax rate multiplied by the risk-free rate.

This provides a rationale for the cost-of-capital rate having a link with the risk-free rate, and today's low-rate environment implies this component of the cost is very small. Agency costs refer to the cost to the shareholder that arises from the firm's management doing things with shareholder capital that are not in shareholders' interests. This is perhaps an unusual example of where the regulator might be the friend of the shareholder. Compared with other corporations, insurance company managers are extremely constrained in what they can do with the capital shareholders have provided to fund regulatory solvency requirements. Conceptually, this cost should therefore also be very small for a regulated insurer. The third component conventionally identified for the frictional cost of capital is the cost of financial distress. This relates to the idea that in the event of bankruptcy or near-bankruptcy of the firm, there are a range of costs incurred of which all capital providers share the burden. Again, for a highly regulated and financially secure insurance firm, this risk of bankruptcy and its associated costs will be lower than that of a typical corporation. Typical estimates of the frictional cost of capital for a firm, according to the economics literature, will vary between $2 \%$ and perhaps $4.5 \%$.

I believe for the reasons I have outlined here, that the frictional cost of capital for a UK insurance firm today should be at the very low end of that spectrum. Therefore, I contend that halving the cost-of-capital rate from $6 \%$ to $3 \%$ can be viewed as quite prudent, and a case for a $2 \%$ or even lower assumption could reasonably be made. Clearly, a 3\% assumption would half the risk margin. The calculations provided in section 7 of the paper highlight that such an assumption would reconcile much better with current reinsurance pricing than the assumed rate of $6 \%$. 
I think there are many interesting and important topics on which I have not been able to touch. Do we need a risk margin at all? Can it result in the double counting of risks? Does it result in a potential solvency system that requires too much capital with the inevitable harmful consequences for consumer costs and choices? What should the UK do with the risk margin before it makes departure from the EU? How does it fit with International Capital Standards and Solvency II equivalents and so on? I look forward to hearing the thoughts and comments of others.

The Chairman: Thank you very much, Craig. I hope that sets the scene for some questions and comments. Andy (Pelkiewicz) has taken us through his ticks and crosses, which some of you might disagree with or want to hear more about. Craig (Turnbull) has found a flaw in the Solvency II calibrations, which is certainly fascinating to me.

Mr M. C. Ledlie, F.F.A.: Just a couple of practical observations. I am a director for a number of insurance companies. One of the biggest challenges we have is managing the transitional measure on technical provisions (TMTP), and there is clearly a link from the risk margin through to the TMTP. Anything that can be done that reduces the reliance and helps the quicker roll-off of TMTP would be very welcome, I think, to simplify the management of insurance balance sheets, which that makes incredibly complicated at the moment.

A second observation is that all this theoretical calibration is all well and good, but I think it is assuming that insurance companies are run at $100 \%$ SCR coverage. The reality is all insurance companies need a buffer above that. They will have a risk appetite which sets, potentially, quite a substantial buffer. Many holding companies are running at $200 \%$ coverage of SCR. There certainly seems to be some evidence of buffer upon buffer upon buffer existing. In that context, having a very full risk margin seems unhelpful. Something which sets the base level of solvency at a slightly lower level and allows companies to run with a level of buffer above that regulatory level would seem a more sensible outcome.

The Chairman: Would you rather see a reduction in the buffer, a removal or a reduction in the risk margin, or both of those?

Mr Ledlie: I think it is inevitable that companies must always run with a buffer above the regulator quoted solvency level, just because of the way that markets look at companies. I think some weakening of the base solvency standard through a reduction in the risk margin is probably the sensible way to do that. Even if the capital were the same at the end of the day, I think having it in the buffer above SCR is a better way of doing it.

Mr A. M. Eastwood, F.F.A.: I am still trying to come to terms with Craig (Turnbull)'s comment that the equity risk premium cancels out. The implications seem to be that advocating a reduction in the cost of capital is a sound way forward and one that could be evidenced. I am trying to reconcile that with what I think you said, Andy (Pelkiewicz), none of the members of the working party thought a lower rate could be justified?

Mr Pelkiewicz: I said there were a variety of views and that I did not think that anybody thought a higher rate would be justified.

The Chairman: What do you think has gone wrong with the additional analysis in terms of EIOPA finding that, if anything, the evidence is that the cost-of-capital rate should be going up, rather than coming down?

Mr Turnbull: My understanding is that it is all based on the same logic of simply trying to estimate the equity risk premium for an insurance firm, and it happens to conclude that the risk premium estimate should be higher than $6 \%$, which could be a completely valid result. I do not dispute that analysis. I dispute that it is the right question to ask.

Mr D. J. Grenham, F.I.A.: Given your comments about pushback from PRA and EIOPA, where does this work go? It is a great piece of work, a very good paper and a great summary, but is that the end or do you think there is some life in this and it could have an impact in the future?

Mr Pelkiewicz: I will start with the EU. They, as I said, are having a review next year. The scope of that review has already been defined by the European Commission and as far as risk margin is 
concerned, the scope is limited to the cost-of-capital method, which I found disappointing but perhaps not too surprising. That was set out in a letter from the European Commission to EIOPA. I hope that the scope could be regarded as including a variable cost-of-capital rate, as we suggested as one alternative, but I am not $100 \%$ certain. The various other parts of the cost-of-capital method are up for grabs in that review. Thinking further forwards, Solvency II will always be under continual review. I think it will depend on what happens in the future. I think the pressure on risk margin will be much diminished following Brexit, because nobody else in the EU seems particularly concerned about it. The problems largely relate to the very large UK annuity market.

Switching now to the UK, I think what happens is very much tied in with the details of how Brexit is implemented. I think a strong possibility is that the UK regulatory view would be: leave everything as it is. Therefore, they would reject proposals and suggestions to change the risk margin. On the other hand, they do have to consider what the Treasury Committee said, which was that calibration should be revisited.

I am not sure whether over a slightly longer period the UK would wish to move to something completely different to Solvency II. I could envisage a framework which looks like Solvency II, but which might have specific changes relevant to the UK. On that basis, changes to the risk margin would be possible and one would hope what we have proposed is considered.

The question of equivalence is an interesting one. It seems, from what we understand as a working party, much more relevant for general insurers to have Solvency II equivalences, than for life insurers in the UK. General insurers are not particularly concerned with the risk margin, as I understand it. There might be some specific areas of concern, but it is not as big an issue. If equivalence is seen as desirable for the whole of the UK insurance industry, but changes to the risk margin are desirable for the life industry, there is a potential tension. I think that would perhaps be politically resolved. Mr A. Marshall: Many of the comments so far centre around capital and the balance sheet. Another angle is, if you consider customer outcome, how products are priced? The Treasury Select Committee report brought out the role of regulation as being to encourage competition as well as protecting customers. I wonder if that could give an angle in terms of trying to justify, or support, a reduced risk margin.

The Chairman: One of the peculiar situations that we did not discuss in the presentation was the bizarre situation where the risk margin can be more than $100 \%$ of the solvency capital requirements. Ultimately, the policyholders are paying twice for the level of capital held. Indeed, as per Craig (Turnbull)'s comments earlier on, potentially more than that. Surely that becomes nonsensical. Why has nobody seen the flaw in that so far?

Mr Pelkiewicz: That is a very fair point. Do you regard the risk margin as a part of capital? Technically it is not, but for practical purposes it can be regarded as such. If so, is it too high? You can look at that in many different ways. However low it is, you can probably find somebody saying, "It is still too high, it is affecting pricing." There comes a point where policyholders are inadequately protected. I would say that no risk margin and a 1 -in-200-year SCR is inadequate protection. Other people would say otherwise.

You also related back to Craig (Turnbull)'s point about buffers. Companies are free to choose their own buffer, but the risk margin is part of the required liabilities. If you say we have too much altogether, risk margin plus SCR plus buffer, why not reduce the buffer? A problem is that the buffer is there in case something goes wrong, and if something goes wrong, you still have to hold the risk margin. It is not a complete solution to say, "reduce the buffer."

My feeling is that the risk margin is too high. I think that is the view of most of the working party, but there does need to be sufficient risk margin. There is a danger of saying, "Everything is too much. It is having too much of an impact on the market. Get rid of it all." Then you have more failures. Is that better in the policyholder's interest? You need the right balance.

Mr J. E. Gill, F.F.A.: I was struck by one of the things that Craig (Turnbull) said about the illusory nature of the hedgeability of interest rate risks and insurance risks, and why under 
Solvency II there is such a divide between the two, when their hedgeability is of a similar standard. Why have we not seen the big annuity writers try to demonstrate to regulators and the rest of the world that insurance risks are hedgeable, and indeed putting pressure on reinsurers to make the data available to do so? There is a deep and liquid market in hedging insurance risks. Or would that be a futile task because it would not change the Solvency II rules?

Mr Turnbull: I can talk a little about interest rate risk in the Solvency II example on longevity risk. I am not asserting these risks are similar in terms of the nature of their transferability. The point was that Solvency II is assuming they are by rejecting the use of market prices for long-term Euro interest rates. By rejecting market prices, it is making some sort of statement about the lack of a deep and liquid transfer market. That implies a lack of risk transferability. In my mind, you either use a market parameter or the logic is to use a best estimate parameter and then that implies a risk margin has to be held on top.

In the Euro case, there is an inconsistency because there is no risk margin on top of a best estimate assumption, which is not the case for the longevity rate.

Mr Pelkiewicz: Your question was, as I understood it, can an insurance company use reinsurance pricing to replace that part of the risk margin? The answer, under Solvency II regulation as it currently stands, is that it is not allowed. That is the point I made in the presentation. When Solvency II was originally drafted, it talked about hedgeable and non-hedgeable risks. At some point, fairly early on, the distinction in the definition of the risk margin in the Solvency II delegated regulation was changed. It refers to the risks you have to include in the risk margin as all insurance risks, plus non-hedgeable market risk.

The ABI did come up with a clever solution, which they put to the PRA. My understanding is the PRA thought about it for a while but were never in a position where they felt they could make a decision. The solution was that the firm documents a management action, that if it de-risks its assets, it would automatically reinsure its longevity risk. The logic is that happens, theoretically, the day before you transfer the liabilities to the reference undertaking. The reference undertaking, under Solvency II rules, does assume that all management actions apply in the reference undertaking. The reference undertaking would then automatically be assumed to have longevity reinsurance.

I find that approach unsatisfactory. It is stretching how to interpret the regulations. I suspect the PRA may have the same view, but they were, at the time, under pressure from the Treasury Committee.

The real solution would be to change the delegated regulation to allow the longevity risk solution component of SCR to use reinsurance risk pricing, for the purposes of risk margin. The practical problems will be enormous, but I suspect they could be overcome.

Mr Turnbull: In assessing the cost of financial market risk, illiquid non-transparent prices are used extensively in Solvency II liability valuation. There is no transparent market price for, say, a 10- or 20-year equity index option price, but there are processes that have been used for many years to estimate these costs. Perhaps on an anonymous basis, prices are submitted to some sort of central database. Those submissions are then processed, and central estimates of the prices are published. These prices are then used by all insurers as a basis to form a market consistent calibration.

There is arguably nothing about a reinsurance treaty that looks different to a 30-year over-thecounter derivative in this respect. That suggests that that mechanism could also naturally be permitted in the longevity pricing process.

Mr Pelkiewicz: One possibility, which I alluded to in my presentation but which is not explicitly covered in the paper, is that you could put an artificial cap on the longevity risk portion of SCR for the purpose of calculating risk margin, which could perhaps be defined as X\% of the best estimate. You could justify that cap on the grounds of the existence of reinsurance. Such caps are used in other areas in Solvency II. The Minimum Capital Requirement is an example which has a cap. Mr S. K. Grout, F.I.A.: On that point, it is a while since I have looked at reassurance of longevity in 
a lot of detail. Certainly reassurers had risk appetite limits and prices that could be quite volatile. I am wondering whether or not you would reduce the volatility of that part of the risk margin.

Come October or November, if you have used up your limits on longevity risk with the reassurer, it could cause a spike in exactly the same way that you are trying to avoid through the risk margin. Do others have a more recent experience? Certainly a few years ago that could have been the case.

Mr Pelkiewicz: It was our assumption, based on our anecdotal evidence, that longevity reinsurance pricing is less volatile than risk margin. It is an area which is difficult to verify.

Mr Turnbull: In general, as with all market prices, the price is not a volume-dependant estimate. You are essentially estimating the cost of transferring a pound, not 10 billion or 100 billion. Certainly, when you look at how financial market prices are quoted and used, it is on that basis. To me, the simplest, cleanest way of solving this problem may be to have a regular anonymised survey of reinsurers, asking them to apply pricing quotations for transferring a sample longevity book. That then forms a basis not for the risk margin but for the actual estimation margin in the valuation of the target assumptions itself.

Mr Pelkiewicz: One practical difficulty is that for longevity, the annuity books of insurers vary considerably. If you did as you suggest, you would probably want to make the specimen book prudently defined. I think that would be a possibility and that could feed into the definition of that part of the risk margin, either as a cap or just as a percentage of best estimate.

Mr R. R. Waddell, F.I.A.: I know we touched very briefly on the risk adjustment under IFRS 17 , and we are probably reaching a period where many companies will be finalising setting their methodologies for its calculation. I wondered if you had any views on whether companies will tend to take approaches similar to the Solvency II risk margin, or whether we will see more diversity of approach under IFRS 17 and whether that will have any implications for the discussion around risk margin?

Mr Pelkiewicz: I do not know. We did have, in the working party, some knowledge of IFRS, but I do not think I am in a position to comment.

Dr S. J. Richards, F.F.A.: Just to set expectations regarding the survey idea, it is not obvious to me why an American reinsurer would provide specimen pricing when it is not going to lead to any kind of business. Moreover, the purpose of the survey is to reduce the risk margin, the level of which is driving demand for the very reinsurance they are trying to sell.

The Chairman: The development of the superfunds regime has brought about a completely different way of thinking about liability. Instead of a $99.5 \%$ value at risk (VaR) with a risk margin and a buffer, some are thinking about, for example, a 99\% VaR over the run-off period, or other different mechanisms. Post-Brexit, should we not just discard Solvency II and go for something along the superfunds line?

Mr Pelkiewicz: My instant reaction to that is no. Defining capital requirements over a whole run-off period has some attraction. For life insurance, the idea of a 1-year VaR is, and always was, questionable, but we imported it from banking and took it as an article of faith. With a clean sheet of paper, I could imagine your proposal. On the other hand, Solvency II is a lot more than just how you value the liabilities and the capital. If you discard Solvency II, I would be worried.

Mr D. McCarthy: I understand that for the back book it might not be possible, but going forward, can you ever envisage a scenario where we have competing solvency regimes in the UK for new entrants? For example, pension freedoms allow you to take your money and buy a boat or a car, so why should it not be possible to have a less regulated annuity provider? You would hope, after the buffer, you still hold what the regulator is recommending for Solvency II, but maybe before the buffer, the starting point is lower such that a more competitive price can be offered?

Mr Turnbull: You have just described a superfund, have you not?

Mr McCarthy: Without discarding Solvency II, you can ideally have both.

Mr Turnbull: In the UK, an insurance company means a certain thing, I guess, in terms of the level of security associated with the promise that you receive. To ensure that promise is held at 
certain levels of security, there is regulation around capital. There is no conceptual reason, theoretically, why you could not also market a different thing that was not called an insurance company that offered similar promises but made it clear that the promises were not very secure and call them something else. Providing you do not mis-sell it, which could be interesting, that could work.

The whole superfund movement is essentially going down the route of trying to find the halfway house for pension fund members, who are often in very insecure places just now given the security of the sponsor, and are at risk of losing benefits by going to the Pension Protection Fund (PPF). It becomes a halfway house between the PPF and an insurance company.

Mr Pelkiewicz: It is an interesting idea, and I agree with Craig (Turnbull), it would have to be called something other than insurance. I would go in the opposite direction. Anything which involves long-term guarantees should be regulated to the same high standards. The high standards are necessary because the public, who buy these things, are not sophisticated and there are a lot of cowboys out there. It is a great strength of the UK, and indeed the European insurance industry, that there have been so few failures. I can see the attraction of giving customers a choice of something strongly protected and expensive, or weakly protected and cheap, but I see too many dangers. It is also perhaps a generational aspect. I tend to look at regulation and protection as a good thing, and regard open free markets as dangerous, but perhaps younger people feel the opposite way.

Mr Grenham: In response to that last question and also your comment, I work for a company that provides not insurance but medical malpractice indemnity. You can line us up against an insurance company. We offer indemnity, but we also have the ultimate management action that we can decide not to pay, if we decide not to do so. It means that we are not regulated by Solvency II. We do not have to pay Insurance Premium Tax, and we have no cost of capital. Is this a good thing?

We have been going for 117 years, so we have been doing something right. Unfortunately from our point of view, the government takes your view. Recently, it has been consulting to make all doctors and dentists take out insurance rather than indemnity, which will put up their prices. Because they are doctors, NHS costs flow through to our taxes. If that is the way society wants to go, I suppose we have no choice but to follow it.

The Chairman: I thought this paper was very balanced papers, particularly given there was something of a leading question that was probably given to you off the back of the Treasury Committee. You did an excellent job, Andy (Pelkiewicz), with your team of pulling together something which set out arguments for the risk margin being reduced, considering both the upsides and the downsides, and not just jumping to some of the simpler conclusions.

It was very interesting, Craig (Turnbull), that in your analysis you did find that there was potentially an even simpler answer that perhaps the working party had not reached. I enjoyed the way that you described it Andy (Pelkiewicz), in your light-hearted example, as it being satisfyingly prescriptive. There is something about Solvency II that is probably going to continue being satisfyingly prescriptive for some time. As the debate has shown, prescription is not necessarily right.

We have explored some of the challenges from the policyholders' perspectives of higher premiums. We have explored some of the different potential regimes, which are very interesting and are going to be thrown into the public debate, particularly in the annuity space with pension schemes that may be forced into the PPF versus insurance. This will remain the gold standard, but can everybody afford it?

There is obviously a hard question that some very clever people at the EU have gone away and have decided that $6 \%$ is, if anything, too low. Craig (Turnbull), you are also a clever person and you have gone away and worked out that $6 \%$ is too high. That is probably going to be debated for some time, but the fact that there is empirical evidence that one can go out and transact 
reinsurance at a rate which is significantly below this supposed market consistent level, is really important. That has to be telling us that the answer is probably lower, rather than higher.

The point that the Solvency II balance sheet has multiple different layers of prudence is something that lots of people have landed on and it was certainly something upon which the Treasury Committee picked up.

The idea is that we have best estimate liabilities, which some might argue have some elements of prudence in them, to which we then add a solvency capital requirement. If you are an internal model firm, you have probably incorporated some elements of prudence. We then add the buffer, as you pointed out Craig (Turnbull), and then we have a risk margin on top of that. It is hardly surprising at all that Steven's North American reinsurance companies are rubbing their hands with glee at the fact that they can offer much better pricing than we can offer by leaving it here.

I think it was a really good discussion. Thank you very, very much for participating.

Cite this article: A review of the risk margin - Solvency II and beyond report by the Risk Margin Working Party - Abstract of the Edinburgh discussion. British Actuarial Journal. https://doi.org/10.1017/S1357321720000197 